\title{
Densification and Structural Evolution in Spark Plasma Sintering Process of Mechanically Alloyed Nanocrystalline Fe-23Al-6C Powder
}

\author{
Yuichiro Koizumi ${ }^{1, * 1}$, Takanori Tanaka ${ }^{1, * 2}$, Yoritoshi Minamino ${ }^{1}$, Nobuhiro Tsuji ${ }^{1}$, \\ Kiyoshi Mizuuchi ${ }^{2}$ and Yoshihira Ohkanda ${ }^{2}$ \\ ${ }^{1}$ Department of Adaptive Machine Systems, Osaka University, Suita 565-0871, Japan \\ ${ }^{2}$ Materials Science and Processing Lab., Osaka Municipal Technical Research Institute, Osaka 536-8553, Japan
}

\begin{abstract}
Nanocrystalline Fe-23 at\% Al-6 at\%C alloy powder was produced by mechanical alloying of the mixture of iron powder and aluminum powder (Fe-25 at\% Al) with methanol, and was consolidated into fully dense compact by spark plasma sintering (SPS) at $1273 \mathrm{~K}$. The compacts have nanocrystalline microstructure composed of mixture of $\alpha$-phase grains and $\kappa$-carbide $\left(\mathrm{Fe}_{3} \mathrm{AlC}\right)$ grains whose average grain size is about $50 \mathrm{~nm}$. Although relatively large grains were also observed in places, their sizes were not over a few micrometers. The mechanisms of the densification and the structural evolution during the SPS process are discussed.
\end{abstract}

(Received March 17, 2003; Accepted June 23, 2003)

Keywords: nanocrystal, $\mathrm{Fe}_{3} \mathrm{Al}$, mechanical alloying, spark plasma sintering, iron, aluminum, carbide

\section{Introduction}

$\mathrm{Fe}_{3} \mathrm{Al}$ intermetallic compound has attractive features as high temperature structural material, such as high strength, good oxidation resistance ${ }^{1-3)}$ and low-cost. However, their commercial application has been limited due to their poor toughness at room temperature and limited workability. Grain refinement is one of the most promising methods to improve the room temperature toughness. Recently, excellent mechanical properties of ultra-fine grained or nanocrystalline metal materials have been reported. ${ }^{4-7)}$ Attempts to improve the mechanical properties of $\mathrm{Fe}_{3} \mathrm{Al}$ by the ultra-grainrefinement have been done as well. ${ }^{8-14)}$ Nanocrystalline $\mathrm{Fe}_{3} \mathrm{Al}$ powders have been produced by mechanical alloying (MA). ${ }^{8-14)}$ Ultra-fine grained bulky $\mathrm{Fe}_{3} \mathrm{Al}$ was successfully obtained by consolidating the mechanically alloyed (MAed) powder by HIP. ${ }^{14)}$ Grain size of the $\mathrm{Fe}_{3} \mathrm{Al}$ compacts was smaller than $100 \mathrm{~nm}$. The ultra-fine grained $\mathrm{Fe}_{3} \mathrm{Al}$ exhibited excellent strength and ductility. Yield stress about $2 \mathrm{GPa}$ and compressive ductility of over $30 \%$ plastic strain were obtained. ${ }^{14)}$ However, the MA process and the HIP process are both time-consuming and not so productive. The milling time for obtaining the nanocrystalline $\mathrm{Fe}_{3} \mathrm{Al}$ was no less than 10 hours. $^{14)}$ In HIP process, powders must be sealed into stainless steel capsules before the pressing. Degassing is also required before the sealing process. The encapsulated powder must be hold at high temperature under high pressure for several hours. More speedy processes are desirable.

Spark plasma sintering (SPS) is a newly developed sintering method which can produce relatively large (over $100 \mathrm{~mm}$ in diameter $)^{15,16)}$ and near-net-shape compacts of high relative density much more rapidly than other conventional process such as pressure-less sintering, hot press and HIP. SPS has been applied to an increasing number of materials successfully. It is expected that rapid consolidation of the MAed nanocrystalline $\mathrm{Fe}_{3} \mathrm{Al}$ powder is also possible

\footnotetext{
${ }^{* 1}$ Corresponding author, E-mail address: koizumi@ams.eng.osaka-u.ac.jp

${ }^{* 2}$ Graduate Student, Osaka University. Present address: JFE Steel Corporation, Kurashiki 712-8511, Japan.
}

by applying SPS. Further, it has been reported that liquid hydrocarbons or alcohols, which were used as processcontrol agents (PCA) to inhibit adhesion of powder during MA, enhanced the alloying process, that is, nanocrystalline $\mathrm{Fe}_{3} \mathrm{Al}$ was produced in a shorter milling time by the addition of PCA. ${ }^{89)}$ Therefore, the combination of PCA-added MA proccess and SPS process is hopeful to shorten the processing time.

However, the influence of the PCA on the composition of MAed powder and the resultant microstructure of the compact is still unclear. Furthermore, the mechanisms of densification by SPS is also still under discussion, and therefore, structural evolutions during the SPS process is not predictable at present. In this study, $\left(\mathrm{Fe}_{3} \mathrm{Al}\right)_{1-x} \mathrm{C}_{x}$ nanocrystalline powder was produced by mechanical alloying of the mixture of iron powder and aluminum powder with methanol as PCA. The MAed powder was consolidated by SPS. The microstructures of the compacts were investigated in detail. The influence of PCA, the densification mechanism and the structural evolution in the SPS process are discussed.

\section{Experimental Procedure}

Elemental iron (10-100 mesh, 99 mass\% purity) and aluminum (100 mesh, 99.78 mass\% purity) powders were mixed in an atomic ratio of $3: 1.20 \mathrm{~g}$ of the mixed powder and $1 \mathrm{ml}$ of methanol were loaded in a stainless steel (SUS304) vessel with $238 \mathrm{~g}$ of stainless steel (SUS304) balls with a diameter of $4 \mathrm{~mm}$ under an argon atmosphere. The inner diameter of the vessel is $50 \mathrm{~mm}$. MA was carried out with a high-energy planetary ball mill (Kurimoto, BX254E) at a centrifugal force of $120 \mathrm{G}$ for $7.2-518.4 \mathrm{ks}$.

The MAed powders were consolidated with an SPS apparatus (IZUMI TECHNOLOGY, SPS-1020) under a vacuum of $2 \mathrm{~Pa}$ at $1073-1273 \mathrm{~K}$ with a sintering pressure of $32 \mathrm{MPa}$. Cylindrical graphite dies and punches were used. The inner and outer diameters of the die were $30 \mathrm{~mm}$ and $70 \mathrm{~mm}$, respectively. $15 \mathrm{~g}$ of the powder were charged in the die and heated under the pressure of $32 \mathrm{MPa}$. This applied 
pressure is limited by the strength of the graphite die and punches. The heating rate was $1.67 \mathrm{~K} / \mathrm{s}(100 \mathrm{~K} / \mathrm{min})$ and the holding time was $300 \mathrm{~s}$. The temperature was measured by a thermocouple inserted into a hall $(2 \mathrm{~mm}$ in diameter and $10 \mathrm{~mm}$ in depth) drilled on the outer cylindrical surface of the die.

The microstructures of the powders and the compacts were characterized by optical microscopy, X-ray diffraction method (XRD), scanning electron microscopy (SEM) and transmission electron microscopy (TEM). The volume fractions of voids in the compacts were evaluated from the optical micrographs on cross sections of the compacts using an image analyzing software (NIH image). The variations of relative density during the SPS processes were estimated from the movements of the piston of the SPS apparatus and the final volume fraction of the voids in the compacts after consolidation. ${ }^{17)}$ The composition analysis was carried out by means of an electron probe X-ray microanalysis (EPMA) at an acceleration voltage of $15 \mathrm{kV}$. A cold fin for prohibiting a contamination of specimen's surface was used in the analysis in order to measure the concentration of carbon accurately. Disks for TEM observation were cut parallel to the pressure axis from the center of the compacts by electro-discharge machining. They were mechanically ground to $30 \mu \mathrm{m}$ thick. The final thinning was done with an atom-milling machine.

\section{Results}

\subsection{Mechanical alloying}

Figure 1 shows the X-ray diffraction profiles of the powders MAed for various periods. The as-mixed powder exhibits sharp peaks from pure $\mathrm{Al}$ and pure $\alpha$-Fe. After MA for $7.2 \mathrm{ks}$, the peaks from $\mathrm{Al}$ had almost disappeared and the

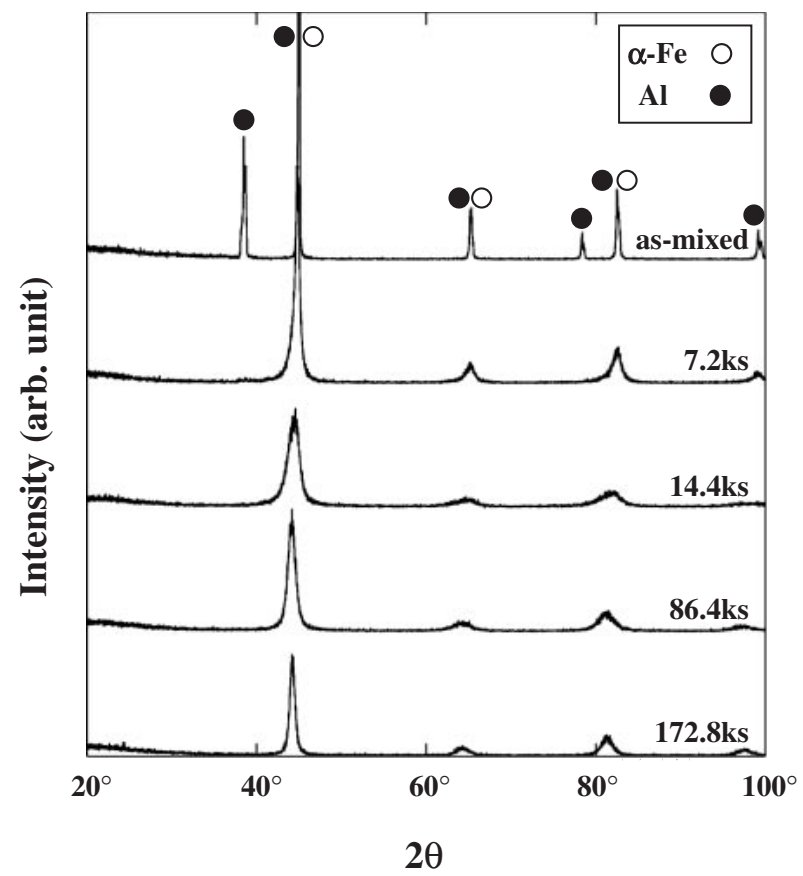

Fig. 1 X-ray diffraction profiles showing structural evolution during mechanical alloying of the mixture of $\mathrm{Fe}$ powder and $\mathrm{Al}$ powder $(\mathrm{Fe}-$ 25 at\% Al) with doped methanol.

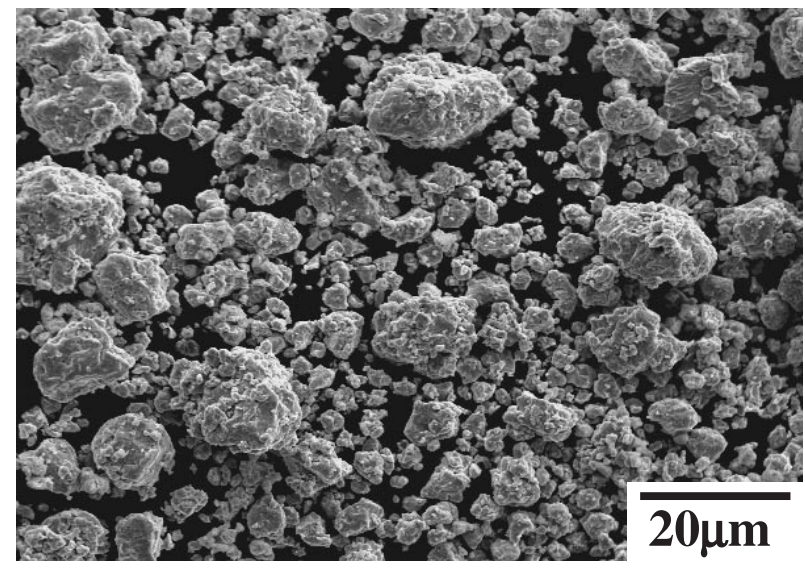

Fig. 2 SEM image of the powder mechanically alloyed for $14.4 \mathrm{ks}$.

peaks from $\alpha$-Fe became broad. After the peaks from the $\alpha$ Fe became broader at $14.4 \mathrm{ks}$, they became sharper at further milling times. This suggests that the grain growth has occurred after $14.4 \mathrm{ks}$. The powder milled for $14.4 \mathrm{ks}$ was chosen for sintering experiments, since it had the smallest grain size. The grain size estimated by Scherrer's equation ${ }^{18)}$ was $5 \mathrm{~nm}$. Figure 2 shows the SEM image of the powder milled for $14.4 \mathrm{ks}$. The shapes of the powder particles are almost equiaxed. The size of the particles varies from submicron to approximately $20 \mu \mathrm{m}$. The volume-weighted average of the size of the powder particle was $6 \mu \mathrm{m}$.

\subsection{Compacts consolidated by SPS}

Figures 3(a)-(c) show optical micrographs on cross sections of the compacts spark-plasma-sintered (SPSed) at various temperatures. Voids were observed as black areas or dots. The compact SPSed at $1073 \mathrm{~K}$ has a lot of voids (Fig. 3(a)), while those SPSed at $1173 \mathrm{~K}$ and $1273 \mathrm{~K}$ have almost no void (Figs. 3(b) and (c)).

Figures 4(a)-(c) show the variations of relative densities during the SPS process at various sintering temperatures as a function of sintering time. The variations of the temperature are indicated together by dashed lines. The initial relative densities were about 0.65 . The relative densities were almost constant while the temperatures were below about $800 \mathrm{~K}$. They began to increase gradually when the temperature exceeded about $800 \mathrm{~K}$. When the temperature was kept at $1073 \mathrm{~K}$, the rate of the densification suddenly decreased as shown in Fig. 4(a). Although the relative density continued to increase at slower rate, the final relative density was no more than 0.837 . On the other hand, when the temperature was raised to $1173 \mathrm{~K}$ or $1273 \mathrm{~K}$ (Figs. 4(b), (c)), the relative density continued to increase rapidly until they reached the almost full densities of 0.995 and 0.996 at $1173 \mathrm{~K}$ and $1273 \mathrm{~K}$ respectively.

Figures 5(a), (b) and (c) show the SEM backscattered electron (BSE) images of the compacts consolidated by the SPS at $1073 \mathrm{~K}, 1173 \mathrm{~K}$ and $1273 \mathrm{~K}$, respectively. Three kinds of solid areas exhibiting different brightness were observed in every compact. Although voids also exhibits dark images as well as the area of high concentration of light elements in the BSE images, one can distinguish the voids by comparing the BSE images with the optical micrographs of the same area. 


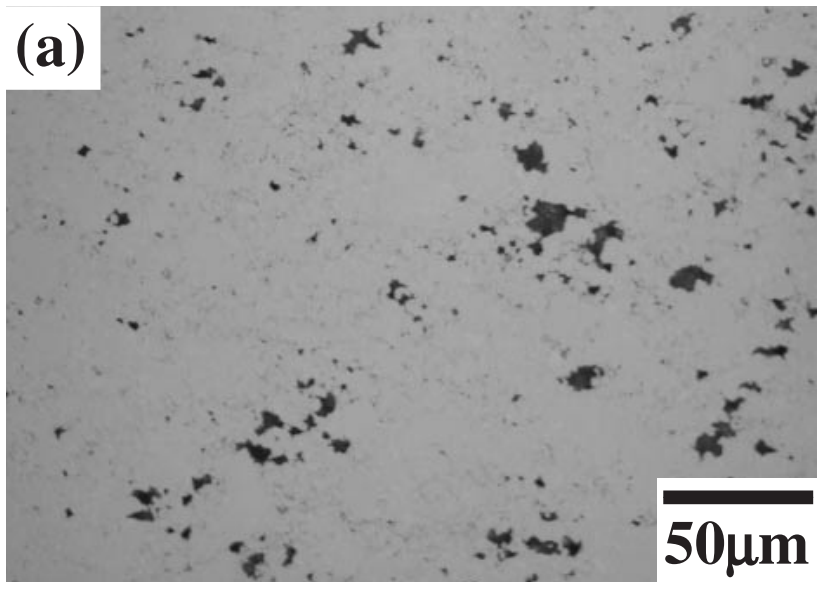

(b)

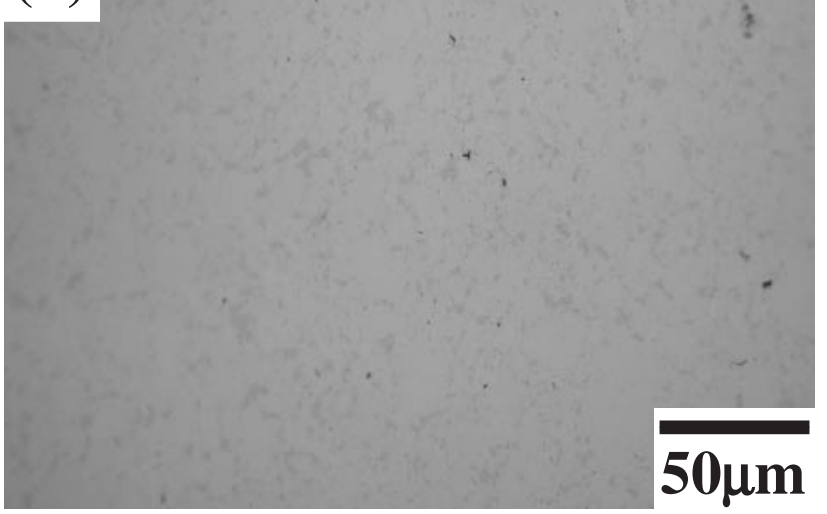

(c)

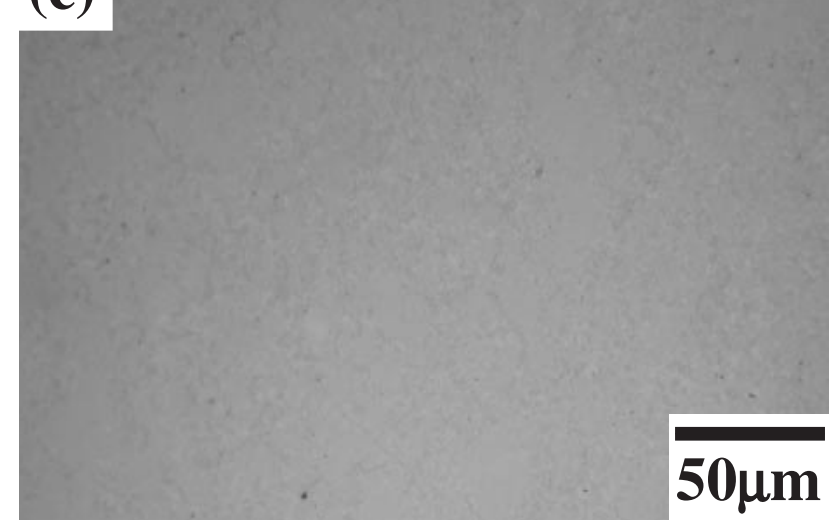

Fig. 3 Optical micrographs on cross sections of the compacts consolidated by SPS at (a) $1073 \mathrm{~K}$, (b) $1173 \mathrm{~K}$ and (c) $1273 \mathrm{~K}$.

Except for voids, the brightest, the darkest and middle gray images were named B-area, D-area and M-area respectively.

In the compact SPSed at $1073 \mathrm{~K}, \mathrm{M}$-areas, whose sizes were smaller than $10 \mu \mathrm{m}$, were observed. Each M-area probably corresponds to the powder particle since their sizes are comparable to the size of the as-MAed powder particles. Mixtures of the three kinds of small areas were observed between the micron-sized M-areas with significant amount of voids together. In the compact SPSed at $1173 \mathrm{~K}$, the microstructure is similar to that in the compact SPSed at $1073 \mathrm{~K}$ except that there is almost no void. In contrast, the quite different microstructure was formed at $1273 \mathrm{~K}$. Small dark dots were observed inside of the M-areas. The B-areas
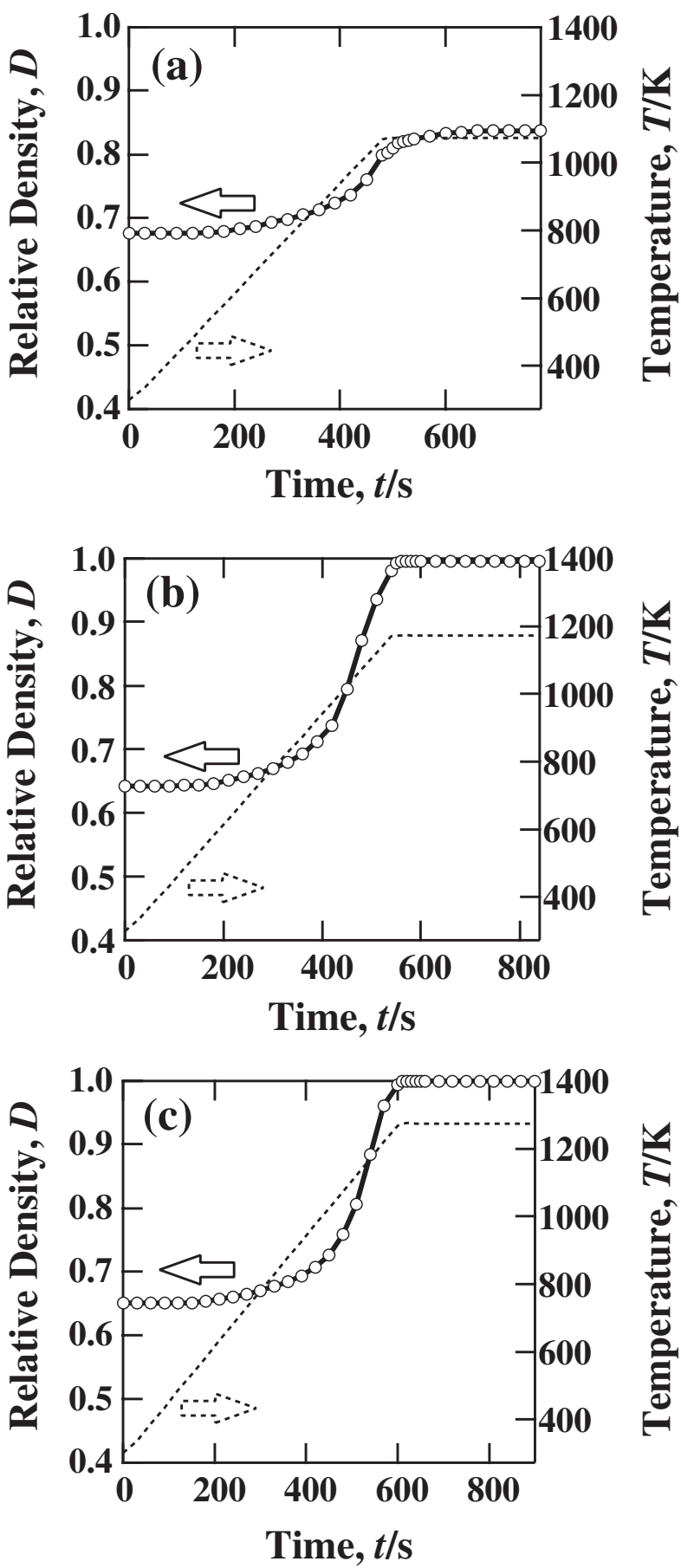

Fig. 4 Variations of relative densities of the compacts as a function of sintering time in SPS with different sintering temperatures of (a) $1073 \mathrm{~K}$, (b) $1173 \mathrm{~K}$ and (c) $1273 \mathrm{~K}$. Variations of temperature are shown with dashed lines together.

were much larger.

Table 1 shows the fractions of the three kinds of the solid areas except for the voids. The area fractions in the compacts SPSed at $1073 \mathrm{~K}$ and $1173 \mathrm{~K}$ were similar to each other. In contrast, the area fractions of the B-area and the D-area in the compact SPSed at $1273 \mathrm{~K}$ were considerably different from those of the compacts SPSed at lower temperatures. The area fraction of the B-area was 4-6\% larger, and that of the D-area was $5-7 \%$ smaller than in the compacts SPSed at lower temperatures.

Table 2 shows the chemical compositions measured by 

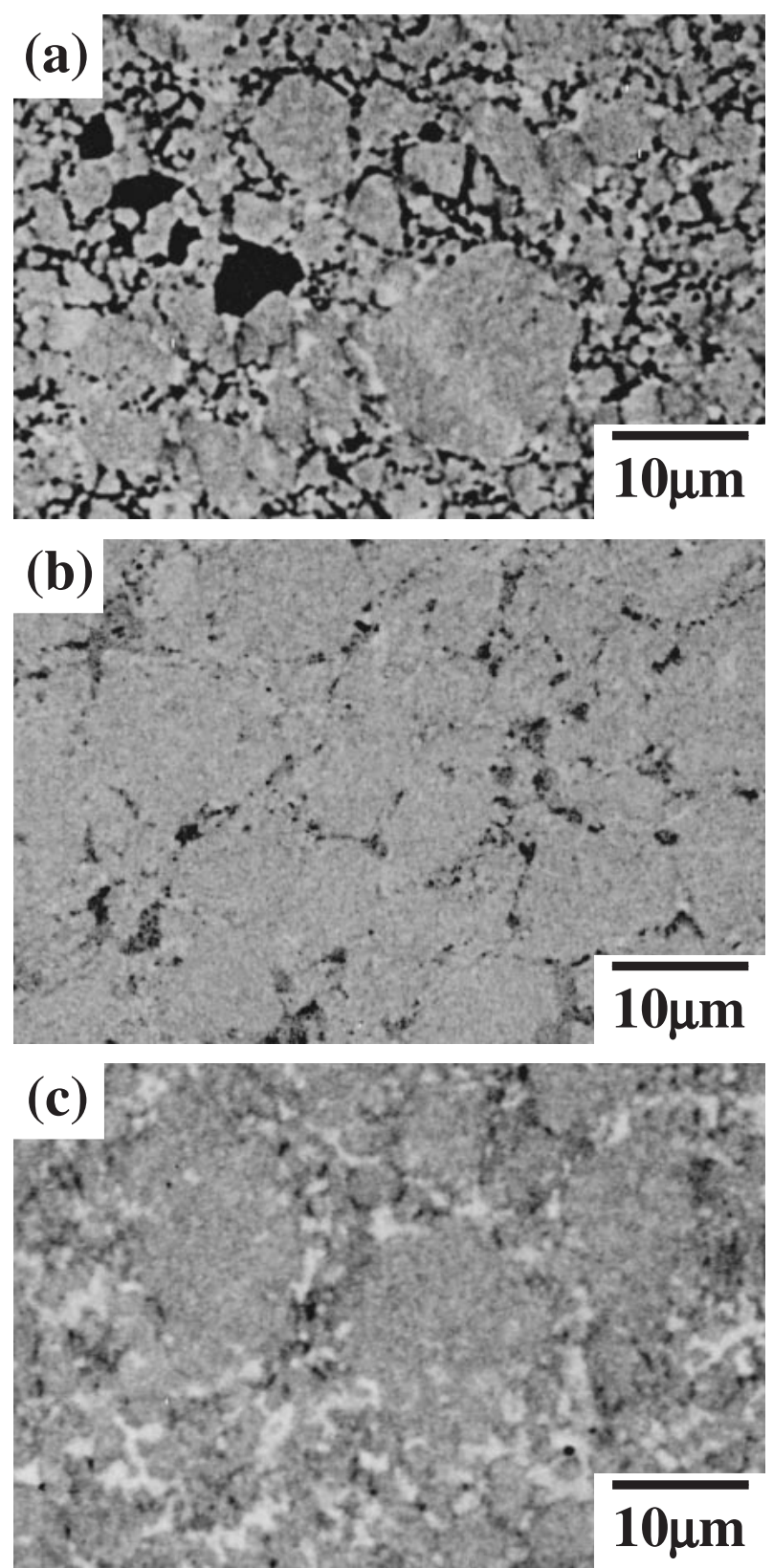

Fig. 5 SEM backscattered electron images of the compacts consolidated by SPS at (a) $1073 \mathrm{~K}$, (b) $1173 \mathrm{~K}$ and (c) $1273 \mathrm{~K}$.

EPMA at each area in the compact SPSed at $1273 \mathrm{~K}$, which has the maximum relative density. Significant amounts of carbon were included in every area. This carbon is supposed to be from the methanol which might have been decomposed during the MA process. Such carbon from PCA has been observed in MAed Ti-Al alloy as well. ${ }^{19)}$ Small amount of chromium and nickel from the stainless steel balls and the vessel used in the MA process were also included in every area. The mean composition of the compact roughly estimated from the volume fraction and the composition of each area (Tables 1 and 2) is Fe-22.6 at\% Al-6.0 at\%C0.3 at $\% \mathrm{Cr}-0.2$ at $\% \mathrm{Ni}$. If all the carbon included in the methanol was doped into the mechanically alloyed powder, the chemical composition of the loaded powder should be $\mathrm{Fe}-23.5$ at\% $\mathrm{Al}-5.7$ at\% (impurities in elemental powders, oxygen and hydrogen in the methanol are neglected). These
Table 1 Fractions (\%) of the areas showing different brightness in SEM backscattered electron images of the compacts consolidated by SPS at various temperatures.

\begin{tabular}{cccc}
\hline \multirow{2}{*}{ Temperature, $T / \mathrm{K}$} & \multicolumn{3}{c}{ Area } \\
\cline { 2 - 4 } & Bright & Middle & Dark \\
\hline 1073 & 11.7 & 78.3 & 10.0 \\
1173 & 10.1 & 82.0 & 7.9 \\
1273 & 15.7 & 81.0 & 3.3 \\
\hline
\end{tabular}

Table 2 Chemical compositions (at \%) of the areas with different brightness in the compact consolidated by SPS at $1273 \mathrm{~K}$.

\begin{tabular}{cccccc}
\hline Area & Fe & Al & C & Cr & Ni \\
\hline B-area & Bal. & 19.2 & 5.1 & 0.3 & 0.2 \\
M-area & Bal. & 23.1 & 6.1 & 0.3 & 0.2 \\
D-area & Bal. & 27 & 7 & 0.3 & 0.1 \\
\hline
\end{tabular}

measured and prepared compositions are quite similar to each other. This means that almost all carbon in the methanol was alloyed into the powder during the milling process. The atomic ratio of iron and aluminum $(3: 1)$ was maintained in the M-area. The concentrations of aluminum and carbon in the B-area were about 4 at $\%$ lower and 1 at $\%$ lower than in the M-area, respectively. On the other hand, the concentrations of aluminum and carbon in the D-area were 4 at $\%$ higher and 1 at $\%$ higher than in the M-area, respectively. Since the D-areas were so small compared to the electron probe size in the EPMA that the X-rays from the surrounding $\mathrm{M}$-area might be included in the measurement. Therefore, the actual concentrations of aluminum and carbon in the D-area are probably higher than 27 at $\%$ and 7 at $\%$, respectively.

Figure 6 shows the X-ray diffraction profiles of the asMAed powder and the compacts SPSed at various temperatures. While only the peaks from $\alpha$-Fe are seen in the

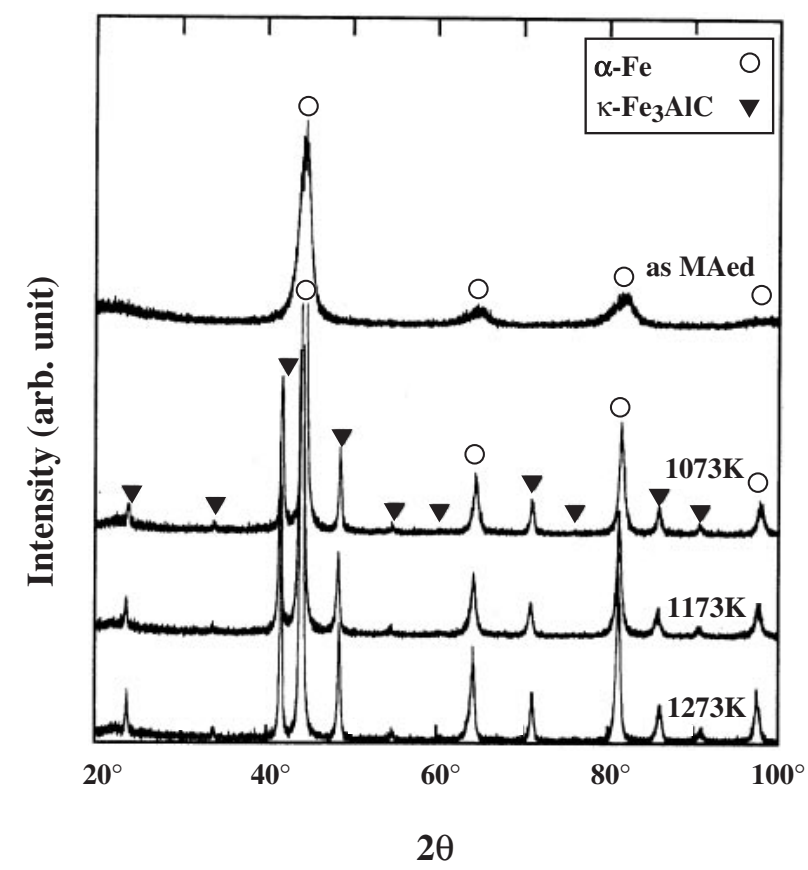

Fig. 6 X-ray diffraction profiles of the mechanically alloyed powder and the compacts consolidated by SPS at various temperatures. 
profiles of the as-MAed powder, the peaks from $\kappa$ - $\mathrm{Fe}_{3} \mathrm{AlC}$ carbide are seen in addition to the peaks from $\alpha$-Fe in every profile of the SPSed compacts. This means that $\kappa$-carbide was formed during the SPS process and that all the compacts consist of $\alpha$-Fe and $\kappa$-carbide. Therefore, the D-areas in the SEM images are thought to be $\kappa$-carbide phases. The peaks from the $\alpha$-Fe are sharper in the profiles of the SPSed compacts than in the profile of the as-MAed powder. This indicates that grain growth have occurred during the SPS process at every temperature tested. No superlattice reflection from ordered $\mathrm{Fe}_{3} \mathrm{Al}$ was observed. This is probably due to the carbon addition which might inhibit the formation of the ordered structure.

\subsection{Microstructure observation by TEM}

Figures 7(a) and (b) show the TEM microstructures in the compact SPSed at $1273 \mathrm{~K}$. The compact was mainly composed of the Nano-grains with average grain size of $50 \mathrm{~nm}$ as shown in Fig. 7(a). The corresponding selected area diffraction pattern (SADP) taken by the use of an aperture of $0.5 \mu \mathrm{m}$ in diameter is also shown beside the image. The SADP indicates that $\alpha$-Fe and $\kappa$-carbide $\left(\mathrm{Fe}_{3} \mathrm{AlC}\right)$ with $\mathrm{E} 2{ }_{1}$ structure coexist in the nano-grained area. This area is thought to correspond to the M-area which had the largest area fraction among the three kinds of areas in the SEM backscattered electron image (Fig. 5(c)). Besides the nano- grains, relatively coarse grains with grain size above $1 \mu \mathrm{m}$ were observed as shown in Fig. 7(b). The SADP indicates that such large grains are also $\alpha$-Fe. Faint and small dots were seen within such large grains. These dots imply the existence of defects or nano-sized particles. In the case that the reflecting condition was nearly equal to the Bragg's condition, such large grains exhibited mottled contrast indicating the existence of wavy coherency strain fields. An example of such mottled contrast is shown in Fig. 8 with the corresponding SADP together. In the SADP, spots of 110 reflection from $\kappa$-carbide were found at fixed positions in addition to the diffraction pattern of $\alpha$-Fe. Therefore, the dots in the coarse $\alpha$-grain are thought to be coherently precipitated $\kappa$-carbide particles. Since the intensity of the diffraction spots from $\kappa$ carbide are weaker than in the SADP of the nano-grained area, it seems that the amount of or $\kappa$-carbide or carbon in this region is smaller than in the nano-grained area. Accordingly, the large $\alpha$-grains are thought to correspond to the $\mathrm{B}$-area in the BSE image (Fig. 5(c)).

Figure 9 shows the dark field image of a relatively large $\kappa$ carbide grain with the corresponding SADP together. The $200_{\kappa}$ reflection indicated by an arrow was used for the imaging. Since the $200_{\kappa}$ reflection is very close to the $\{110\}_{\alpha}$ ring, some small $\alpha$-grains are also seen together. The size of the $\kappa$-carbide grain is over $500 \mathrm{~nm}$. Similar coarse $\kappa$-carbide grains were observed in places. Such coarse $\kappa$-carbide grains
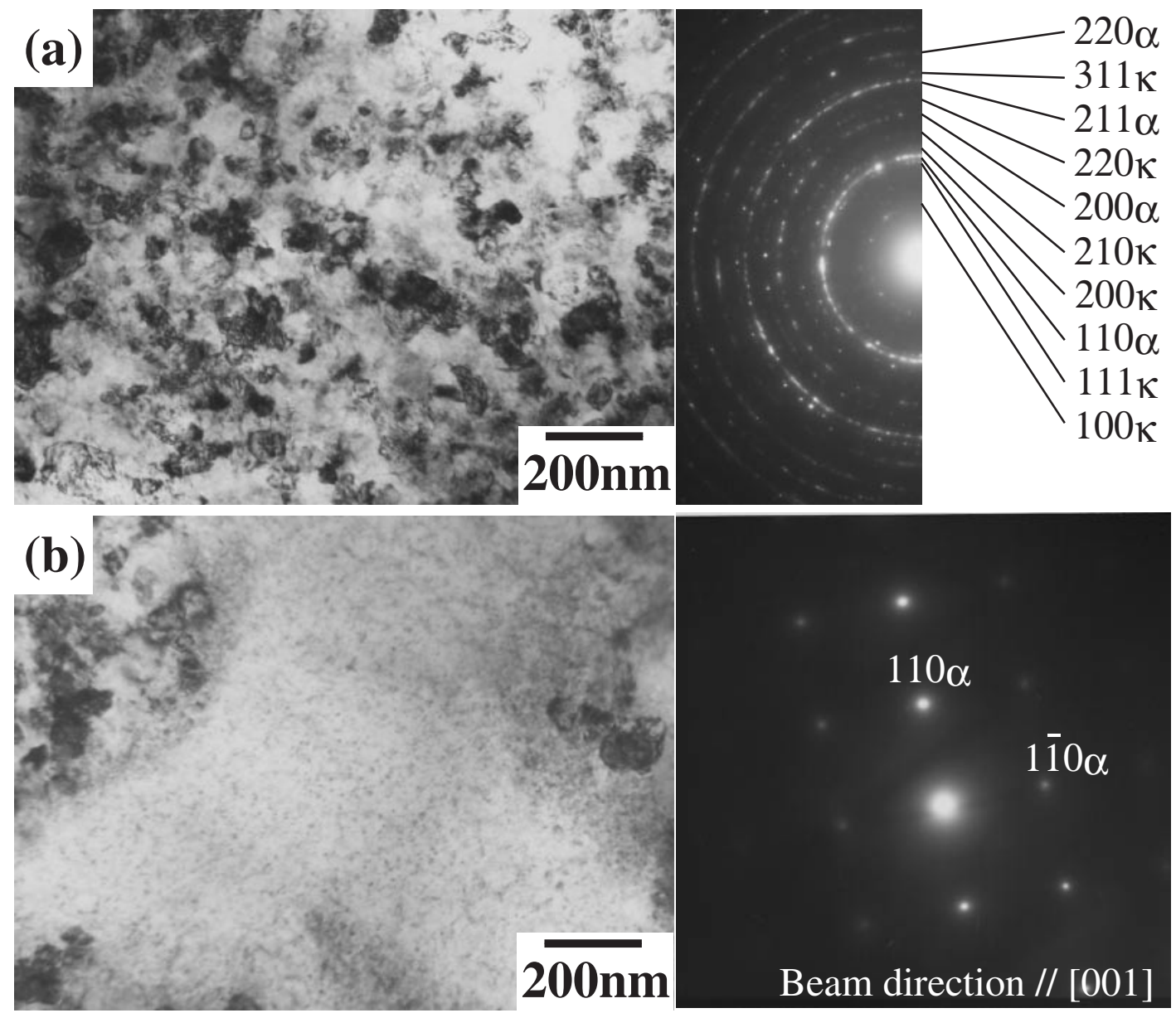

Fig. 7 TEM images of the compact consolidated by SPS at $1273 \mathrm{~K}$, (a) Nano-grains. (b) Relatively coarse grain. Corresponding SADPs are shown together. 

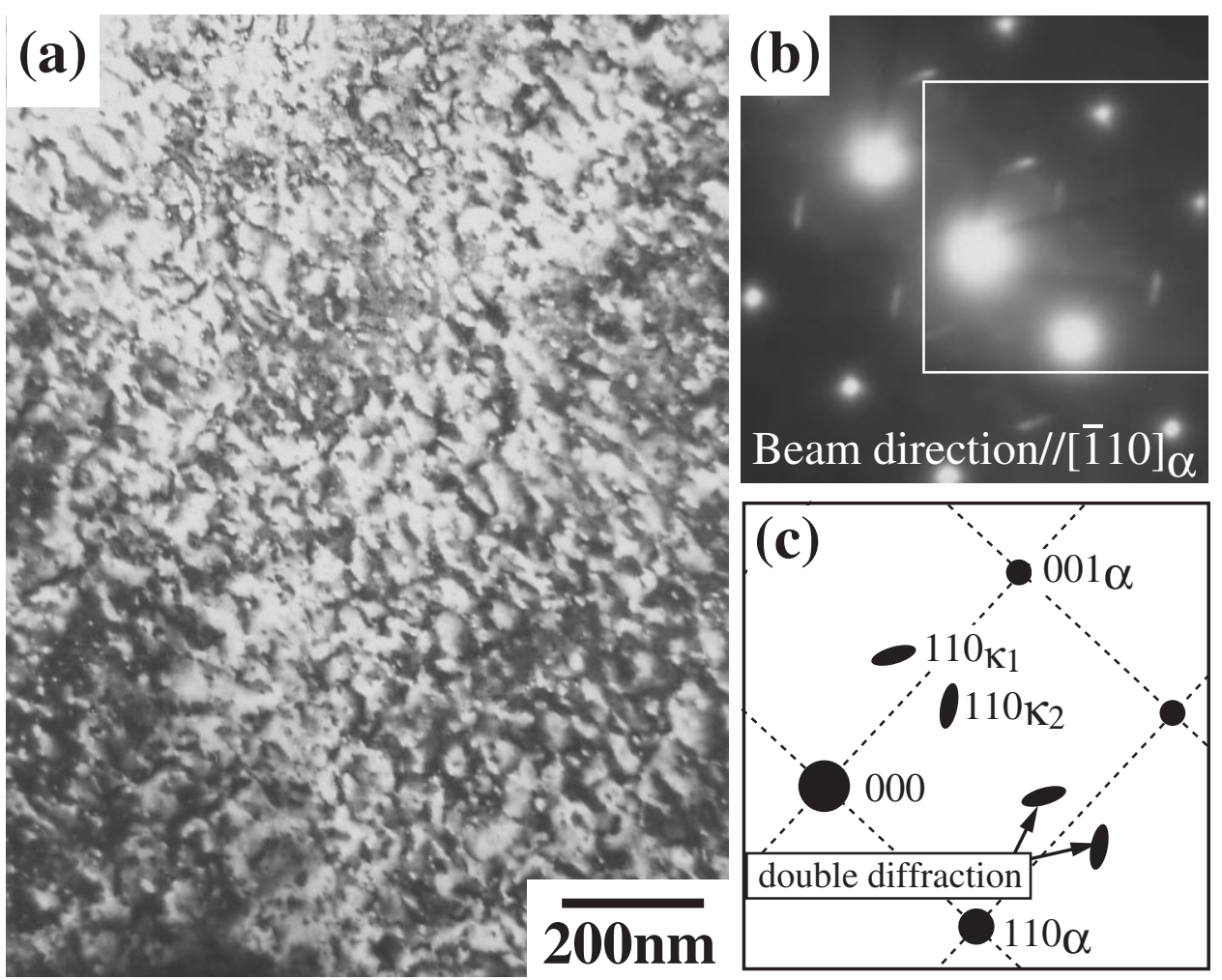

Fig. 8 (a) Bright field image of a coarse grain taken with beam direction near [1110] direction of $\alpha$-Fe. (b) Corresponding SADP. (c) Indices of spots surrounded by white lines in (b).

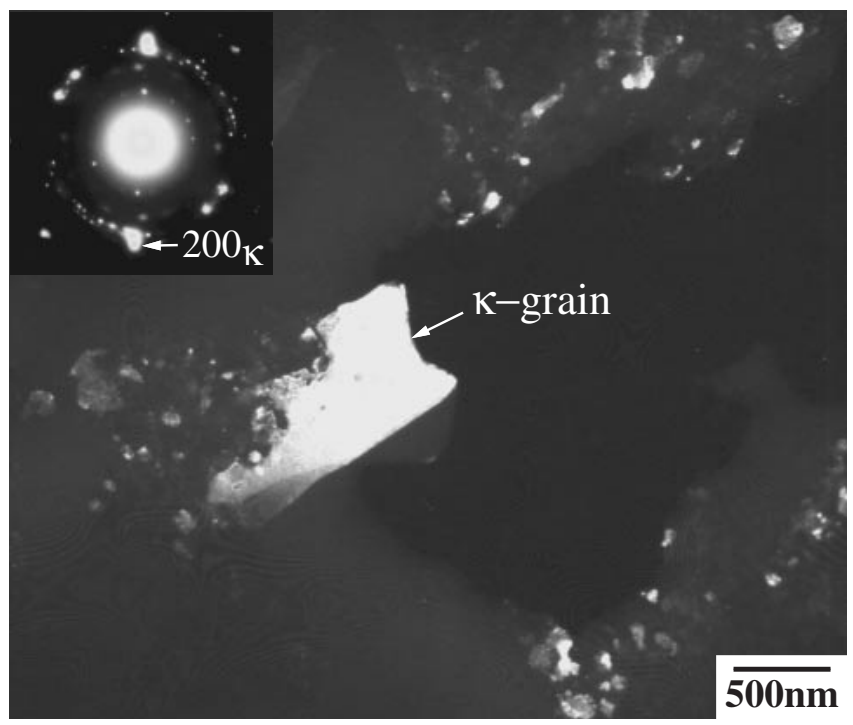

Fig. 9 Dark field image of a relatively coarse $\kappa$-carbide in the compact SPSed at $1273 \mathrm{~K}$. Corresponding SADP is shown together.

are considered to correspond to the D-area in the BSE image (Fig. 6(c)).

\section{Discussion}

\subsection{Densification mechanism in the SPS process}

Densification mechanisms in SPS processes are under discussion, while the densification mechanisms in HIP process have been investigated in detail. The variation of relative density during HIP process has already been under- stood quantitatively. ${ }^{20)}$ Arzt et $a .^{20)}$ considered 'plastic yielding', 'power-law-creep' and 'diffusion from the particle contact boundary to the void surface' as main densification mechanisms in HIP. They derived equations expressing the relative densities obtained by these mechanisms as functions of time, temperature, pressure and some parameters which depend on the material, for example, diffusion coefficients, yield stress and so forth.

Generally speaking, there are two fundamental differences between the densification by SPS and that by HIP. The first is that the spark between powder particles may occur in the SPS, although it has not been confirmed yet directly. However, the effect of the spark on the kinetics of the densification in the SPS process of this study is thought to be very small as explained below. The spark at the gaps between powder particles should occur more frequently in the early stage of the densification than in the later stage since the number of the gaps decreases with increasing relative density. If the spark significantly contribute to the densification, the relative density would increase rapidly in the early stage of the SPS process. On the contrary, the experimentally measured variation of the relative density was very small in the early stage (Fig. 4). Therefore, it can be said that the contribution of the spark to densification is quite small. The second difference is that the applied pressure is unidirectional in SPS while it is isostatic in HIP process. On the other hand, it has been known that quasi-isostatic pressing can be used as an alternative to HIP. In quasi-isostatic pressing, a compact is embedded in a die filled with a granular powder. It is possible to apply isostatic pressure to the embedded compact by utilizing a granular powder as a pressure-transmitting medium. $^{21)}$ Since the powder particles produced in the 
present study are granular (Fig. 2), the stress is also isostatic in the inner part of the compact except for near the surface. On the other hand, the stress is not isostatic near the surface of the compact because of the friction between powder particles and the inner surface of the die and the punches. But the friction should be very small in the case of this study, since the die and the punches are made of graphite, which has low friction coefficient, and the applied pressure is relatively small (32 MPa). Therefore, it is likely that the effect of the friction is quite small and the stress is almost isostatic in the most part of the compact in the SPS process with the graphite die and punches as well as in HIP. Accordingly, the densification theory for HIP can be roughly applied to the densification by the SPS process. The variation of the relative density during the SPS process was calculated by utilizing the equations for the densification by HIP as in the following.

Azart et al. ${ }^{20)}$ presented equations expressing the variation of the relative density by each elemental mechanism as in the followings on the assumption that the stress is isostatic. The relative density obtained by plastic yielding $\left(\rho_{\text {yield }}\right)$ is expressed as follows:

if $\rho \leq 0.9$,

$$
\rho_{\text {yield }}=\rho_{0}+\frac{-1+\sqrt{1+(10 \pi \cdot p) /\left(3 \sigma_{\mathrm{y}}\right)}}{20}
$$

if $\rho>0.9$,

$$
\rho_{\text {yield }}=1-\exp \left(-\frac{3 p}{2 \sigma_{\mathrm{y}}}\right)
$$

where $\rho$ is the relative density, $\rho_{0}$ the relative density at start of pressing, $\sigma_{\mathrm{y}}$ the yield stress of the powder particle material and $p$ the applied pressure.

The densification rate by power-law-creep $\left(\dot{\rho}_{\text {PLC }}\right)$ is expressed as follows:

if $\rho \leq 0.9$,

$$
\dot{\rho}_{\mathrm{PLC}}=5.3 \times\left(\rho^{2} \rho_{0}\right)^{1 / 3} \cdot \frac{x}{R} \cdot \dot{\varepsilon}_{0} \cdot\left(\frac{p_{\text {eff }}}{3 \sigma_{0}}\right)^{n}
$$

if $\rho>0.9$,

$$
\dot{\rho}_{\mathrm{PLC}}=\frac{3}{2} \dot{\varepsilon}_{0} \frac{\rho(1-\rho)}{\left\{1-(1-\rho)^{1 / n}\right\}^{n}}\left(\frac{3 p_{\mathrm{eff}}}{2 n \sigma_{0}}\right)^{n}
$$

where $x$ is the neck radius, $R$ the particle radius, $\left(\dot{\varepsilon}_{0}, \sigma_{0}, n\right)$ the power-law creep parameters and $p_{\text {eff }}$ the effective pressure.

The densification rates by diffusion $\left(\dot{\rho}_{\text {diffusion }}\right)$ is expressed as follows:

if $\rho \leq 0.9$,

$$
\begin{aligned}
\dot{\rho}_{\text {diffusion }} & =\frac{12 \rho^{2}}{\rho_{0} R^{3} g(\rho)} \cdot \frac{\left(\delta D_{\mathrm{b}}+s D_{\mathrm{v}}\right)}{k T} \cdot \Omega \cdot Z \cdot p_{\text {eff }} \\
g(\rho) & =\left[\left(\rho / \rho_{0}\right)^{2 / 3}-1\right]\left\{7.3+15.5\left[\left(\rho / \rho_{0}\right)^{2 / 3}-1\right] / 4\right\}
\end{aligned}
$$

if $\rho>0.9$,

$$
\begin{aligned}
\dot{\rho}_{\text {diffusion }}= & 54 \cdot \frac{\Omega \cdot\left(\delta D_{\mathrm{b}}+r D_{\mathrm{v}}\right)}{k T R^{3}} \cdot h(\rho) \cdot p_{\text {eff }} \\
h(\rho)= & {\left[1-(1-\rho)^{2 / 3}\right] /\left\{3(1-\rho)^{2 / 3}\right.} \\
& \left.-\left[1+(1-\rho)^{2 / 3}\right] \ln (1-\rho)-3\right\}
\end{aligned}
$$

where $\delta D_{\mathrm{b}}$ is the grain boundary diffusion coefficient times the boundary thickness, $s$ the radius of curvature of neck, $D_{\mathrm{v}}$ the lattice diffusion coefficient, $\Omega$ the atomic volume, $k$ the Boltzmann constant, $T$ the temperature, $Z$ the average number of contact neighbors per particle and $r$ the pore radius.

The relative densities were calculated using these eqs. (1)(6). The details of the parameters used in the calculation are shown in Appendix. Figure 10(a) shows the calculated relative density as a function of time for the applied pressure ( $p$ ) of $32 \mathrm{MPa}$ and the sintering temperature $(T)$ of $1273 \mathrm{~K}$ with the experimental data for comparison. The calculated relative density and the experimentally measured relative density are shown by a thick line and solid circles respectively. The calculation is fairly in good agreement with the experimental data except that there is small deviations in the initial stage and just before the full density is obtained at about $600 \mathrm{~s}$. This indicates that the stress condition in the SPS is quite similar to that in HIP, that is, the stress is homogeneous and isostatic. Therefore, the variation of the relative density in the SPS process can be understood by the same densification mechanisms as in HIP.

The increment of the relative density is divided into three parts corresponding to the three elemental densification mechanisms; the diffusion mechanism, the power-law-creep mechanism and the plastic yield mechanism, as shown in Figs. 10(a) and (b). In the initial stage (from $0 \mathrm{~s}$ to about 200 s), the calculated $\rho$ increases only by the plastic yield.
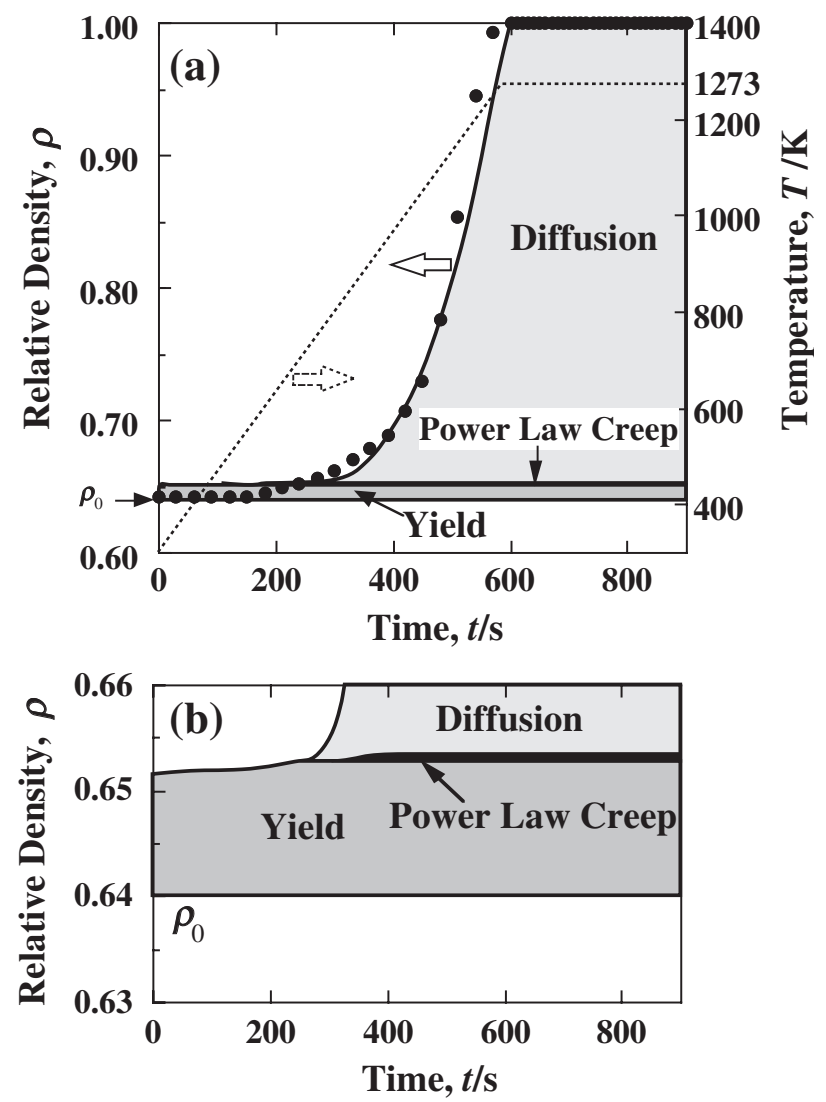

Fig. 10 (a) Calculated relative density as a function of sintering time. Variation of temperature and experimental data are shown by dashed line and solid circles respectively. (b) Magnified drawing. 
The experimental $\rho$ was a little smaller than the calculated $\rho$. This is probably attributed to the difference between the yield stress of the powder particles produced by MA in this study and that used in the calculation, which is the yield stress of cast alloy. ${ }^{22)}$ The MAed powder has nanocrystalline microstructure, while the cast $\mathrm{Fe}-\mathrm{Al}-\mathrm{C}$ alloy has a coarse-grained microstructure. The nanocrsytalline powder is considered to be much harder than the coarse-grained ingots.

In the middle stage (from about 200 to about $600 \mathrm{~s}$ ), the calculated $\rho$ rapidly increases mainly by the diffusion mechanism. The power-law-creep also partly contributes to the densification in this stage, although the increment of $\rho$ by the power-law-creep is small (about 0.001). The quite small contribution of the plastic yield and the power-law-creep is in contrast with the general case of HIP process where plastic yield and power-law-creep significantly contribute to the densification of metal powders. ${ }^{20)}$ This is probably due to the small applied pressure of $32 \mathrm{MPa}$, which is limited by the strength of the graphite die and punches used in the SPS apparatus. The relative density reaches almost 1 around $600 \mathrm{~s}$, and therefore, there is no change in the relative density in the subsequent holding time, that is, in the final stage (after about $600 \mathrm{~s}$ ). The small deviation between the calculation and the experimental data at the end of the middle stage may be inaccuracy of the parameters used and/or the structural evolution at high temperature as noted in the next section.

\subsection{Formation mechanism of coarse $\alpha$-grains}

The coarse $\alpha$-grains are considered to correspond to the Barea in the SEM image (Fig. 5). The B-areas are distributed around the M-areas whose size is comparable to that of the as-MAed powder particles. Therefore, it is likely that the coarse grains were formed near the surface of the powder particles. The formation of the coarse $\alpha$-grain near the surface of the powder particles can be explained as below. The localized heating can occur during SPS process since the Joule heat is concentrated at narrow necks and contacts between powder particles. The temperature at such parts should be higher than the temperature measured at the die. According to a $\mathrm{Fe}-\mathrm{Al}-\mathrm{C}$ ternary equilibrium phase diagram, ${ }^{23)}$ the composition of the MAed powder is in the $\alpha+\kappa$ dual phase region at the sintering temperature of $1273 \mathrm{~K}$. However, the $\gamma$-phase can be formed at parts where the localized heating occur since the $\gamma$-phase is stable in a wider range of composition at higher temperature. Then, the amount of the $\kappa$-carbide precipitates dispersion decreases since a large amount of carbon can dissolve into $\gamma$-phase from the carbides. Therefore, the inhibition of the grain growth by carbides becomes weak in the $\gamma$-phase so that the $\gamma$-grains can grow rapidly. The coarsened $\gamma$-grains are considered to transform into the coarse $\alpha$-grain during cooling by massive transformation. The massive transformation from $\gamma$-phase to $\alpha$-phase has been seen in the $\mathrm{Fe}-\mathrm{Al}$ binary alloys. $^{24)}$ In the case of the massive transformation, one $\gamma$-grain transforms into one or small number of $\alpha$-grains since the $\gamma / \alpha$ interface move very quickly. In contrast, in the case of the diffusional transformation, one $\gamma$-grain would be divided into a certain number of small $\alpha$-grains forming a cluster. In practice, the coarse $\alpha$-grains were observed separately not in cluster. Furthermore, in the case of the massive transformation, the $\kappa$-carbides would precipitate within the $\alpha$-grain after the transformation since carbon should be excessively solved in the $\alpha$-grains just after the massive transformation. This coincides with the fact that the nano-sized $\kappa$-carbides have precipitated in the coarse $\alpha$ grains. Thus, the formation of the coarse $\alpha$-grains can be attributed to the inhomogeneity of heating, the formation of the $\gamma$-grain and the $\gamma$ to $\alpha$ massive transformation. The localized heating and the formation of the coarse grains may be responsible for the fact that the experimentally measured relative density was slightly higher than the calculated one just before the temperature had reached $1273 \mathrm{~K}$ in the SPS process (Fig. 10(a)).

\section{Conclusions}

In the present study, nanocrystalline $\mathrm{Fe}-23$ at $\% \mathrm{Al}-6$ at $\% \mathrm{C}$ powder was produced by mechanical alloying of elemental powderes of iron and aluminum with methanol. The nanocrystalline powder could be consolidated into fully dense compacts with nanocrystalline microstructure in a very short time of $600 \mathrm{~s}$ by means of the SPS process at $1273 \mathrm{~K}$. The average grain size of the nanocrystalline microstructure was $50 \mathrm{~nm}$. Although relatively large grains were partly formed, their grain sizes $(\sim 1 \mu \mathrm{m})$ were much smaller than those formed by conventional thermo-mechanical treatment. Therefore, it is still expected that the compacts exhibit superior mechanical properties. Furthermore, the calculation results of the variation in the relative density during the SPS process indicated that the densification proceeds mostly due to the diffusion. This implies that much faster densification at lower temperature would be possible by increasing the applied stress to the level where the plastic yield and the power-law-creep can contribute to the densification. It would realize more homogeneouly nanocrystallined microstructure.

\section{Acknowledgements}

This work was supported by "Priority Assistance of the Formation of Worldwide Renowned Centers of Research - The 21st Century COE Program (Project: Center of Excellence for Advanced Structural and Functional Materials Design)" from the Ministry of Education, Sports, Culture, Science and Technology of Japan.

\section{REFERENCES}

1) C. G. McKamey, J. H. De Van, P. F. Tortorelli and V. K. Sikka: J. Mater. Res. 6 (1991) 1779-1805

2) K. Giza, H. Bala, J. J. Wyslocki and S. Szymura: Intermetallics 6 (1998) 357-362.

3) C. T. Liu, E. H. Lee and C. G. McKamey: Scr. Metall. 23 (1989) 875880.

4) S. X. McFadden, R. S. Mishra, R. Z. Valiev, A. P. Zhilyaev and A. K. Mukherjee: Nature 398 (1999) 684-686.

5) F. A. Mohamed and Y. Li: Mater. Sci. Eng. A298 (2001) 1-15.

6) S. Takeuchi: Scr. Mater. 44 (2001) 1483-1487.

7) H. Hidaka, T. Tsuchiyama and S. Takaki: Scr. Mater. 44 (2001) 15031506.

8) G. H. Fair and J. V. Wood: Powder Metall. 36 (1993) 123-128.

9) G. H. Fair and J. V. Wood: J. Mater. Sci. 29 (1994) 1935-1939.

10) M. Jain and T. Christman: Acta Metall. Mater. 42 (1994) 1901-1911. 
11) E. Bonetti, G. Scipione, G. Valdre, S. Enzo, R. Frattini and P. P. Macri: J. Mater. Sci. 30 (1995) 2220-2226.

12) L. He and E. Ma: Mater. Sci. Eng. A204 (1995) 240-245.

13) L. He and E. Ma: J. Mater. Res. 11 (1996) 72-80.

14) S. M. Zhu and K. Iwasaki: Mater. Trans., JIM 40 (1999) 1461-1466.

15) M. Tokita: J. Soc. Powder Tech. Japan 30 (1993) 790-804. (in Japanese)

16) O. Yanagisawa, T. Hatayama and K. Matsugi: Materia Japan 33 (1994) 1489-1496. (in Japanese)

17) K. Mizuuchi, M. Fukusumi, M. Sugioka, M. Tanaka, M. Itami and Y. Okanda: Kagaku-to-Kogyo 74 (2000) 100-105. (in Japanese)

18) B. D. Cullity: Elements of X-ray Diffraction, (Adddison-Welsley Publishing Company, Inc., Reading, 1978).

19) K. Ameyama, O. Okada, K. Hirai and N. Nakabo: Mater. Trans., JIM 36 (1995) 269-275.

20) E. Arzt, M. F. Ashby and K. E. Easterling: Metall. Trans. A 14A (1983) 211-221.

21) E. A. Olevsly, E. R. Strutt and M. A. Meyers: J. Mater. Proces. Tech. 121 (2002) 157-166.

22) R. G. Baligidat, A. Radhakrishna, A. Datta and V. V. Rama Rao: Mater. Sci. Eng. A313 (2001) 117-122.

23) M. Palm and G. Inden: Intermetallics 3 (1995) 443-454.

24) J. J. Wits, T. A. Kop, Y. V. Leeuwen, J. Seitsma and S. V. D. Zwang: Mater. Sci. Eng. A A283 (2000) 234-241.

25) D. V. Kolluru and R. G. Baligidad: Mater. Sci. Eng. A328 (2002) 58 61.

26) Z. S. Tôkei, J. Bernardini and D. L. Beke: Acta Mater. 47 (1999) 13711378.

27) H. Mehrer, M. Eggersmann, A. Gude, M. Salamon and B. Sepiol: Mater. Sci. Eng. A239-240 (1997) 889-898.

\section{Appendix}

Parameters used in the calculation of the densification rates are shown below.

$\sigma_{\mathrm{y}}$ (yield stress of particle material):

Yield stresses of $\mathrm{Fe}-28.5$ at $\% \mathrm{Al}-1.1$ at $\% \mathrm{C}$ was used. ${ }^{22)}$ Yield stresses at temperatures where there is no data were estimated by interpolation.

$\dot{\varepsilon}_{0}, \sigma_{0}, n$ (power-law creep parameters):

Parameters evaluated from the creep test data of $\mathrm{Fe}_{3} \mathrm{Al}-$ 0.5 mass $\%$ C were used. ${ }^{25)}$

$\delta D_{\mathrm{b}}$ (grain boundary diffusion coefficient times the boundary thickness):

Data of grain boundary diffusion of $\mathrm{Fe}$ in $\mathrm{Fe}-25$ at $\% \mathrm{Al}$ were used. $^{26}$

$D_{\mathrm{v}}$ (lattice diffusion coefficient):

Data of self-diffusion of $\mathrm{Fe}$ in $\mathrm{Fe}-26.5$ at\% $\mathrm{Al}$ were used. ${ }^{27)}$ $\Omega$ (atomic volume): $1.22 \times 10^{-19} \mathrm{~m}^{3}$

Mean atomic volume of $\mathrm{Fe}_{3} \mathrm{Al}(\mathrm{Fe}-25 \mathrm{at} \% \mathrm{Al})$ at room temperature was used.

$R$ (particle radius): $6 \mu \mathrm{m}$

Average particle size was measured from a SEM image of the mechanically alloyed powders.

The $x$, the $p_{\text {eff }}$, the $s$, the $Z$ and the $r$, which are functions of the relative density $(\rho)$, were calculated from the parameters shown above using the equations developed by Arzt et al. ${ }^{20)}$ for each $\rho$. 